\title{
INFECÇÃO POR POLIOMA VÍRUS APÓS TRANSPLANTE RENAL: RELATO DE CASO
}

\author{
Post-renal transplantation Polyomavirus infection: A case report \\ Kellen Micheline Alves Henrique Costa', José Bruno de Almeida', Ricardo Humberto de Miranda Félix², \\ Maurício Ferreira da Silva Júnior², Marcelo Fabiano de Franco ${ }^{3}$
}

\section{RESUMO}

A nefropatia por poliomavírus ocorre em 1,1\% a 9,3\% dos pacientes transplantados renais, causando perda do enxerto em mais de $40 \%$ dos casos. A infecção primária ocorre durante a infância e o vírus se mantém latente no organismo, sendo reativado em estados de imunossupressão. Relatamos o caso de uma mulher de 45 anos transplantada renal há três anos, em uso crônico de tacrolimo e micofenolato mofetil, que apresentou perda progressiva da função renal durante episódio diarréico, mesmo com tratamento adequado. Biópsia do enxerto renal revelou presença de células com inclusões por poliomavírus, sendo iniciado sirolimo e imunoglobulina humana. Com a terapêutica instituída, houve melhora da função renal e nova biópsia realizada após a internação não demonstrou alterações histológicas de poliomavírus.

Descritores: Vírus BK; Transplante de rim; Imunossupressão

\section{Instituições:}

${ }^{1}$ Serviço de transplante renal do Hospital Universitário Onofre Lopes (HUOL), Natal/RN

${ }^{2}$ Universidade Federal do Rio Grande do Norte - Doutorandos do $12^{\circ}$ período do curso de Medicina, Natal/RN

${ }^{3}$ Serviço de patologia da Escola Paulista de Medicina (UNIFESP), São Paulo/SP

\section{Correspondência:}

Kellen Micheline Alves Henrique Costa.

Av Hermes da Fonseca, 1142, Apto.900, Ed. Pablo Neruda, CEP 59020-315, Natal, RN. Tel: (84) 9991-3935

E-mail:kmahc@uol.com.br.

\section{INTRODUÇÃO}

A Nefropatia pelo vírus polioma ocorre em quase $10 \%$ dos pacientes transplantados renais, ${ }^{1}$ chegando a causar perda do enxerto em mais de $40 \%$ dos $_{\text {casos. }}{ }^{2} \mathrm{O}$ vírus $\mathrm{BK}$, que pertence à subfamília polioma e tem afinidade especial para o trato urinário tem sido reconhecido como um agente que pode causar perda ou disfunção do rim, especialmente em estados de imunossupressão. ${ }^{3}$ A infecção primária ocorre durante a infância ${ }^{4}$ e chega a infectar $80-90 \%$ da população adulta. ${ }^{2,5}$

A maior parte das nefrites induzidas por poliomavírus ocorrem dentro do primeiro ano pós-transplante renal (TxR), embora $25 \%$ dos casos sejam diagnosticados tardiamente, com taxas de perda do enxerto superiores a $40 \%$, segundo diferentes séries. ${ }^{2}$ Os fatores de risco mais importantes para o desenvolvimento da nefropatia pelo BKV são: rejeição aguda e utilização de tacrolimo (TAC) e micofenolato mofetil (MMF) como manutenção terapêutica. ${ }^{1}$

Relatamos a seguir um caso de Nefropatia por poliomavírus pósTxR em uma paciente em uso de TAC e MMF, que evoluiu com nefropatia crônica grave. 


\section{RELATO DE CASO}

Paciente de 45 anos, sexo feminino, do lar, solteira, natural e procedente de Mossoró-RN, com história de insuficiência renal crônica há seis anos decorrente de nefropatia hipertensiva, em hemodiálise (HD) desde 2003. Foi submetida a TxR (doador cadáver) em fevereiro de 2007. Evoluiu com NTA (necrose tubular aguda), sendo necessário HD por 20 dias. Recebeu alta em uso de TAC (5mg/dia) e MMF ( $1 \mathrm{~g} / \mathrm{dia})$, com Creatininina $(\mathrm{Cr})=1,58$ e diurese satisfatória.

Em setembro de 2007 foi admitida com quadro de diarréia (baixa e sem sinais de infecção) há uma semana, associado a dor abdominal, palidez cutâneo-mucosa, astenia e perda de peso (1,5kg em uma semana). Ao exame, apresentava estado geral regular, vígil e orientada, muito descorada, desidratada $(+/ 4+)$, afebril, eupnéica, FC 71bpm, PA 120X80mmHg, emagrecida (peso 37,3kg), acianótica, anictérica, sem adenomegalias, exame cardiopulmonar e neurológico sem alterações. Abdômen era plano, pouco doloroso a palpação difusamente, sem visceromegalias, com rim transplantado palpável em fossa ilíaca direita.

Exames admissionais revelaram: Hb 7,39g/dl, Ht 22,3\% (VCM 92 $\mu^{3}$ e HCM 30,5pg), leucócitos $6660 / \mathrm{mm}^{3}$ (segmentados $4460 \mathrm{~mm}^{3} /$ linfócitos $1670 / \mathrm{mm}^{3}$ ), plaquetas $309000 / \mathrm{mm}^{3}$, Cr 2,2mg/dl, Ur $80 \mathrm{mg} / \mathrm{dl}, \mathrm{Na}^{+} 156 \mathrm{mEq} / \mathrm{l}, \mathrm{K}^{+} 5,4 \mathrm{mEq} / \mathrm{l}, \mathrm{Ca}^{++}$8,1g/dl, $\mathrm{Mg}^{++}$2,44mg/dl, $\mathrm{P}^{+++} 7,4 \mathrm{mg} / \mathrm{dl}$, ácido úrico 5,5mg/dl, TGO 18U/1, TGP 5U/1, fosfatase alcalina 210U/l, gama GT 32U/l, bilirrubina total 0,39mg/dl, glicose $148 \mathrm{mg} / \mathrm{dl}$, colesterol total $145 \mathrm{mg} / \mathrm{dl}$, urocultura negativa. Sorologia para citomegalovírus (CMV) IgG positiva (sem aumento dos títulos, considerando a sorologia do início do transplante) e $\operatorname{IgM}$ negativa. Avaliação pregressa de exames laboratoriais pós-TxR revelou que houve melhora progressiva da função renal, com estabilização da Cr sérica dois meses pós-TxR com níveis de 1,5mg/dl, e proteinúria de 543mg/24h no mês anterior a internação, atribuída a nefropatia crônica do enxerto (NCE). Os níveis séricos de TAC variaram de acordo com esperado para o tempo de TxR, com algumas variações atribuídas ao uso incorreto da medicação pela paciente. Não houve evidência de queda abrupta da hemoglobina que pudesse sugerir aplasia medular por parvovírus, sangramento agudo ou anemia hemolítica, sendo a anemia relacionada à NCE (Figura 3). A variação do VCM no período foi de 80 a $89,4 \mu^{3}$, com ferritina de $152 \mathrm{ng} / \mathrm{ml}$ e saturação de transferrina de $54 \%$ em julho.

Foi medicada com sintomáticos, eritropoetina recombinante humana e mantida em terapia imunossupressora com MMF (1g/ dia) e TAC (4mg/dia), com melhora do estado geral e resolução do quadro diarréico no $2^{\circ}$ dia de internação hospitalar (DIH). Entretanto, houve piora da função renal $\left(\mathrm{Cr} 7,73 \mathrm{mg} / \mathrm{dl}\right.$ no $\left.4^{\circ} \mathrm{DIH}\right)$, sendo necessária terapia dialítica. Exame parasitológico e pesquisa de leucócitos nas fezes foram negativos. Nível sérico de TAC era de $4,5 \mathrm{ng} / \mathrm{ml}$.

Biópsia renal foi analisada no serviço de patologia da Unifesp e evidenciou rejeição aguda túbulo-intersticial leve Banff 97, tipo IA (escores g0, i2, t2, v0), nefropatia crônica moderada do enxerto Banff 97, grau II (escores cg0, ct2, ci2, cv1, ah1, $\mathrm{mm} 0$ ), pielonefrite aguda bacteriana e presença de células com inclusões por poliomavírus (figura 1). Imunohistoquímica com peroxidase anti-sv40 confirmou a presença do vírus (figura 2) e a imunofluorescência foi compatível com padrão de glomerulopatia não-imune e ausência de depósitos fluorescentes glomerulares. Pesquisa do vírus na urina não foi realizada.
Dessa forma, o MMF foi substituído por sirolimo associado à imunoglobulina humana na dose de $18,5 \mathrm{~g} / \mathrm{dia}(0,5 \mathrm{~g} / \mathrm{kg} / \mathrm{dia})$ por seis dias. Cefepime foi administrado devido à presença de picos febris intermitentes associados à pielonefrite sobreposta. Com a terapêutica instituída houve melhora progressiva da função renal, recebendo alta com $\mathrm{Cr}$ 2,1mg/dl, sem anemia e exame físico normal, em uso de prednisona 5mg/dia, sirolimo 3mg/dia e TAC 6 mg/dia. Biópsia renal após quatro meses da alta confirmou erradicação das lesões por polioma, mas revelou nefropatia crônica grave (Banff 97 grau III) e imunohistoquímica demonstrou ausência do vírus.

Figura 1: Alterações citopáticas em células de túbulo renal causadas por poliomavirus

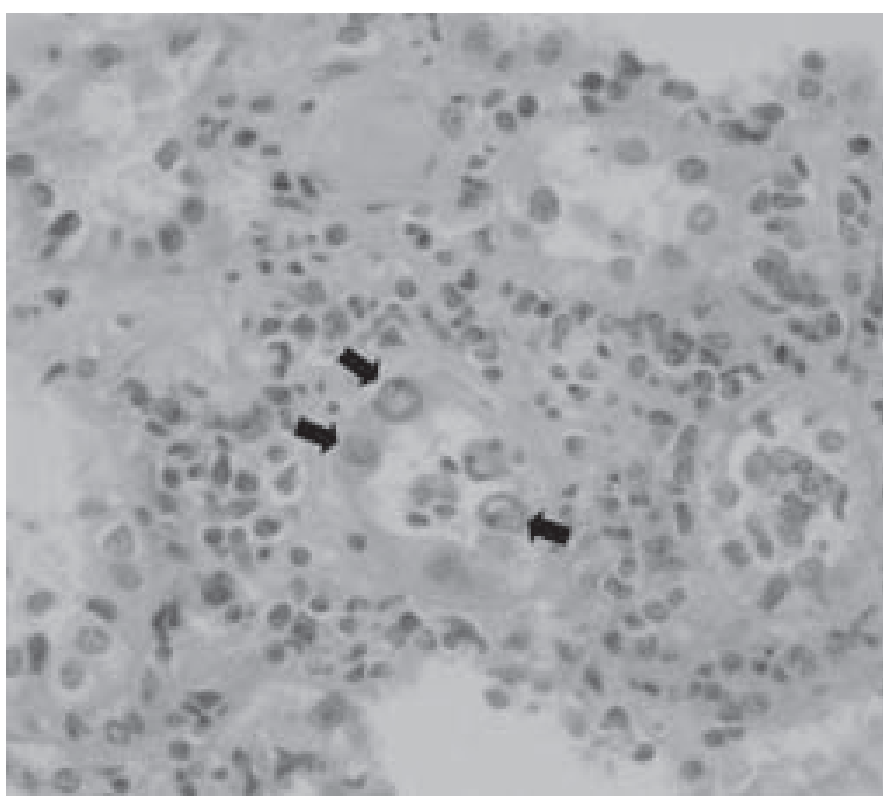

Figura 2: Imunohistoquímica anti sv40 positiva, confirmando infecção poliomavirus

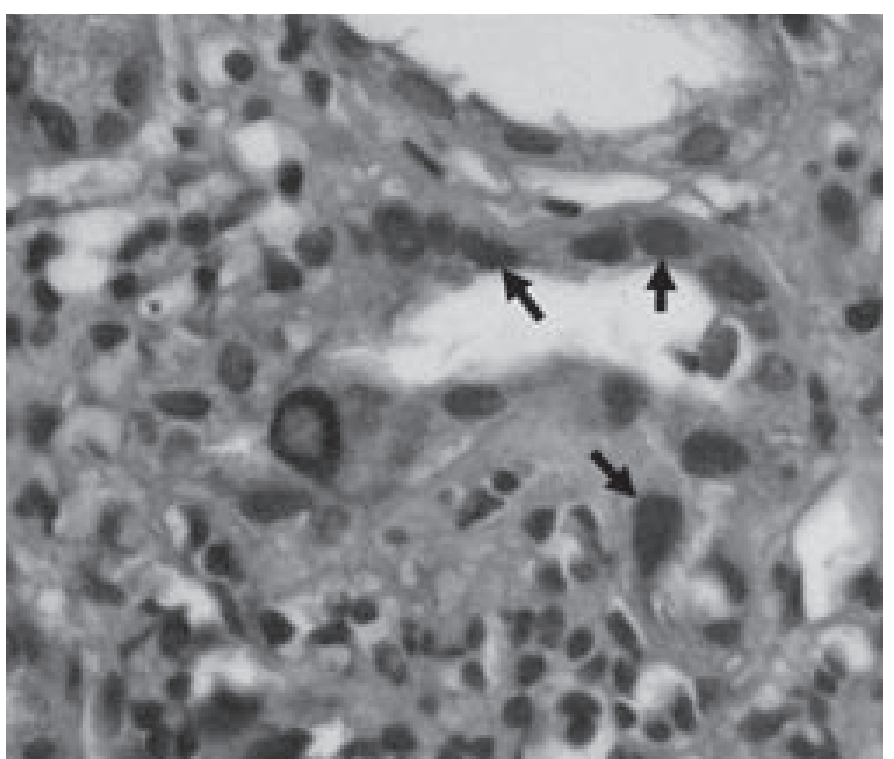


Figura 3: Valores da creatinina, hemoglobina e níveis séricos de tacrolimo pós transplante renal

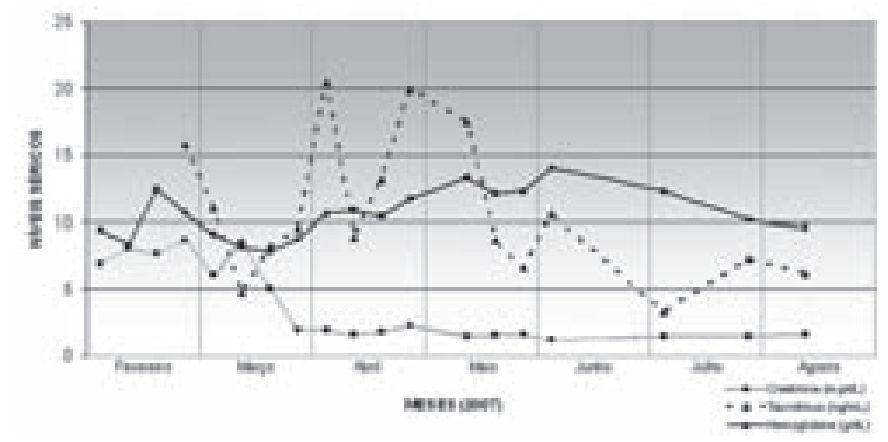

\section{DISCUSSÃO}

Relatamos caso de Nefropatia pelo poliomavírus pós-TxR em uma paciente em uso de TAC e MMF, que evoluiu com nefropatia crônica grave.

A Nefropatia pelo vírus polioma ocorre em 1,1\% a 9,3\% dos pacientes transplantados renais, ${ }^{1}$ causando perda do enxerto em mais de $40 \%$ dos casos. ${ }^{2}$ Esses pacientes devem receber imunossupressores por longo tempo, para evitar rejeição do enxerto, o que os tornam susceptíveis a infecções e neoplasias, causas importantes de morbimortalidade nesses doentes. ${ }^{3}$

Os poliomas vírus humanos pertencem à família papovavírus, subfamília polioma. O vírus BK (BKV) tem afinidade especial para o trato urinário, sendo reconhecido como um agente causador de perda ou disfunção renal. Já o vírus JC (JCV) é associado à leucoencefalopatia multifocal progressiva. ${ }^{1,3}$ Este apresenta $72 \%$ de homologia na sua seqüência de nucleotídeos com o vírus BK, enquanto o vírus simiesco 40 (SV40) apresenta 70\% em partes homólogas com a seqüência nucleotídica de ambos. ${ }^{6}$

A infecção primária pelo BKV ocorre durante a infância, por meio do trato gastrointestinal ou respiratório. É geralmente assintomática, embora possa ocasionalmente produzir sintomas no trato respiratório superior ou urinário. ${ }^{4}$ Após a infecção primária, o vírus se mantém latente em diferentes locais, principalmente no trato geniturinário (rins, bexiga, próstata, cérvix, vulva, testículos) e nos tecidos hemato-linfóides (amígdalas e células mononucleares do sangue periférico), e pode ser reativada pelo estado de imunossupressão desses pacientes. Dentre a população adulta, 80-90\% é BKV-soropositivo. ${ }^{5}$

Em pacientes transplantados renais, pode produzir cistite hemorrágica, estenose ureteral e nefrite tubulointersticial com risco de progressão para perda do enxerto. ${ }^{4,5}$ Hematúria, disúria, proteinúria e sinais de infecção generalizada com envolvimento de vários órgãos e febre estão geralmente ausentes, o que dificulta a suspeição clínica. ${ }^{7}$ Como no caso em questão, a maior parte das nefrites induzidas por poliomavírus ocorrem dentro do primeiro ano pósTxR, embora 25\% dos casos sejam diagnosticados tardiamente. As taxas de perda do enxerto chegam a ser superiores a $40 \%$, segundo diferentes séries. ${ }^{2}$

Os fatores de risco mais importantes para o desenvolvimento da Nefropatia por BKV são rejeição aguda e utilização de TAC e
MMF como manutenção terapêutica. ${ }^{1}$ Entretanto, devem-se avaliar fatores inerentes ao doador, ao receptor e ao enxerto. ${ }^{8-10}$ Assim, os fatores relativos ao doador incluem: presença de infecção ativa $\mathrm{BKV}$, infecção por $\mathrm{CMV}$, soropositividade para BKV, bem como doador vivo. Por outro lado, os fatores de risco relacionados ao receptor incluem: idade avançada, sexo masculino, infecção por $\mathrm{CMV}$, diabetes mellitus, soronegatividade para BKV do receptor, e origem caucasiana. Já os fatores de risco relacionados ao enxerto incluem: órgão com danos, uso de stents ureterais e aparecimento tardio da função do enxerto. ${ }^{8-10}$ A paciente em questão, apesar de estar com nível de imunossupressão adequado, com níveis séricos de TAC normais, apresentava alguns fatores de risco, como o esquema de imunossupressão utilizado e rejeição túbulo-intersticial aguda pós-TxR .

Imunossupressão é o principal fator de risco para infecção ativa por BKV, especialmente com a manutenção de terapia combinada com TAC e MMF, bem como uso da terapia anti-linfocitária para rejeição aguda.,8-12 O impacto real do tipo de imunossupressores, e particularmente suas combinações é claramente avaliado em um estudo prospectivo por Brennan, cujos dados assinalaram que é a intensidade da imunossupressão, mais do que o tipo de drogas, o que confere o risco mais alto de infecção por BKV, e, portanto, para a nefrite associada. ${ }^{11}$ As maiores taxas de viremia foram observadas com a associação TAC e MMF e as menores com ciclosporina e MMF. Além disso, o estudo revela concretamente como o acompanhamento e a retirada rápida das medidas antimetabólicas após a detecção da viremia foi associada à resolução da mesma e ausência de nefropatia sem ocorrência de graves eventos ou rejeição e perda do enxerto. Nível sérico de TAC superior a 8 $\mathrm{ng} / \mathrm{ml}$ ou uma dose de MMF superior a $2 \mathrm{~g} /$ dia foram associados a aumento do risco. ${ }^{12}$

A citologia urinária é muito conveniente, útil e sensível para a avaliação e acompanhamento de pacientes transplantados renais, e pode refletir a apresentação histológica da infecção viral indiretamente através da identificação de células com inclusões virais (decoy cells) podendo ajudar no diagnóstico de replicação ou infecção ativa. ${ }^{1,4,5,8,11,12} \mathrm{O}$ uso de PCR estudando o RNAm das células do sedimento urinário tem sido descrito como um método acurado e não invasivo para estabelecer o diagnóstico. Usandose ponto de corte de $6,5 \times 10^{5}$ cópias da região VP1 do BKV por nanograma do total de RNA na urina, a nefrite pode ser prevista com sensibilidade de 93,8\% e 93,9\% de especificidade. ${ }^{10}$ Entretanto, é um exame disponível apenas nos grandes centros.

O padrão ouro para o diagnóstico da nefrite pelo poliomavírus é a detalhada avaliação da biópsia renal. ${ }^{1,8,10,11}$ Os achados histopatológicos incluem corpos de inclusão intranucleares nas células epiteliais, alterações tubulares e infiltrado intersticial. ${ }^{10,11}$ Esse padrão de nefrite muitas vezes mimetiza a rejeição, gerando dúvidas e tornando o tratamento um dilema. ${ }^{13}$ As técnicas de visualização direta têm o inconveniente de não ser capazes de diferenciar entre os três tipos de poliomavírus que infectam humanos (JCV, BKV, e SV40), e ainda apresenta potencialidade de erro identificando outros vírus, tais como CMV e adenovírus. ${ }^{10}$

O diagnóstico diferencial das inclusões celulares deve ser feito com CMV, adenovírus, e vírus herpes simples humano (HSV). O BKV apresenta inclusões intranucleares basofílicas sem halo circundante, enquanto CMV apresenta inclusões citoplasmáticas. Já as inclusões por HSV estão presentes tanto no núcleo quanto no citoplasma. ${ }^{14}$ As 
alterações vistas à microscopia óptica não são patognomônicas de Nefropatia por BKV, sendo necessário outros métodos diagnósticos, dentre eles a imunohistoquímica, hibridização in situ e microscopia eletrônica. ${ }^{7,8}$

Hirsch ${ }^{15}$ e Nickeleit ${ }^{7}$ propuseram um modelo de patogênese para Nefropatia por BKV em que eliminação assintomática do vírus na urina é seguida por invasão precoce do enxerto com viremia detectável e, subsequentemente, por disfunção renal e lesão microscópica. O estágio mais precoce da lesão consiste em alterações citopáticas nas células tubulares da medula renal. A progressão da doença é caracterizada por invasão viral de todas as camadas de túbulos com degeneração tubular e infiltrado inflamatório. Mais tardiamente, há predominância de atrofia tubular e fibrose intersticial com poucas evidências de presença viral, o que torna difícil a diferenciação com Nefropatia crônica do enxerto.

O tratamento da Nefropatia por BKV é bi-facetada: por um lado, redução da imunossupressão, a fim de restabelecer a imunidade anti-viral, e, por outro lado, terapia específica anti-viral., ${ }^{70,16} \mathrm{~A}$ modificação do esquema imunossupressor tem sido a principal estratégia terapêutica. ${ }^{8}$ Esta tem sido centrada na redução da dose das drogas quando se tem diagnóstico de dano renal no acompanhamento contínuo da imunossupressão no momento do transplante e da modificação da terapêutica mediante a detecção de replicação viral no plasma e urina. Se ocorrer rejeição aguda do enxerto como resultado da redução da terapêutica imunossupressora, recomenda-se a administração de metilprednisolona em pulso. Nesses casos, o tratamento com drogas anti-linfocitárias não é recomendado, pois elas induzem uma maior disfunção imunológica, que promove maior reativação do vírus polioma. ${ }^{10}$

No caso em questão substituiu-se o MMF por sirolimo, minimizando o impacto deletério do primeiro sobre a infecção viral, ${ }^{1,8-12}$ além de melhorar a sobrevida do enxerto em longo prazo, por diminuir a progressão da NCE com o uso da segunda droga. ${ }^{17}$ Já a imunoglobulina humana foi empregada por ser uma opção de tratamento tanto para rejeição aguda, quanto para infecção por poliomavírus. ${ }^{18} \mathrm{O}$ mecanismo de ação desta não envolve apenas transferências de anticorpos, mas também imunomodulação e expressão de receptores Fc, inibição dos danos mediados por complemento, interferências com a rede de citocinas inflamatórias, células dendríticas, macrófagos e linfócitos $\mathrm{B}$ e T ${ }^{10} \mathrm{O}$ real benefício da imunoglobulina humana na Nefropatia pelo poliomavírus ainda é desconhecido. ${ }^{18}$
Na terapêutica, os antivirais são necessários, já que a redução da imunossupressão por si só não pode melhorar significativamente a função do enxerto em pacientes com nefropatia já estabelecida. A terapia específica antiviral é realizada com o uso de leflunamida e, principalmente, com cidofovir, que inibe a síntese do DNA viral. ${ }^{19}$ Utiliza-se a dose de 0,25 a $1 \mathrm{mg} / \mathrm{kg}$ IV a cada três semanas, com anterior hidratação do paciente para reduzir os efeitos nefrotóxicos da droga. ${ }^{20} \mathrm{O}$ cidofovir é atualmente considerado como sendo uma alternativa terapêutica em pacientes não responsivos à redução da imunossupressão e mostrando evidências de deterioração progressiva da função renal. ${ }^{20}$ Os antivirais não foram utilizados por não estarem disponíveis em nosso serviço, sendo a imunoglobulina mais acessível naquela ocasião.

No retransplante, após perda do enxerto renal devido a BKV, observou-se taxa de recidiva da infecção em cerca de $13 \%$ dos pacientes. A maioria deles (73\%) recebeu o mesmo regime imunossupressor utilizado no primeiro transplante. Nesses casos, tem sido recomendado reduzir a intensidade da imunossupressão e evitar retransplante na presença de replicação do BKV. ${ }^{21}$

$\mathrm{O}$ rastreamento pesquisando a replicação do vírus BK é recomendado em doentes com enxerto renal com determinação da viremia, quer através de citologia urinária, quer por via de microscopia eletrônica e, preferencialmente, através de PCR quantitativo. A pesquisa deve ser feita de acordo com os recursos de cada centro de transplante mensalmente, durante os primeiros seis meses pósTxR e, em seguida, trimestralmente ou sempre que for detectada disfunção do enxerto. Em caso de viremia positiva, deve-se realizar biópsia renal, e se existirem provas de Nefropatia por polioma, a imunossupressão deve ser diminuída, devendo ser considerada terapia com leflunomida ou cidofovir. ${ }^{10}$

Relatamos o caso de uma paciente com várias complicações secundárias a TxR, que apresentou quadro diarréico auto-limitado, que não justificava a perda rápida e progressiva da função renal, o que suscitou a necessidade de biópsia renal para elucidação diagnóstica. A associação de rejeição aguda e poliomavírus no enxerto dificulta a escolha da melhor opção terapêutica, já que o excesso de imunossupressão contribui para progressão da infecção viral e a minimização da mesma implica na piora da rejeição. Nesse cenário, a imunoglobulina é uma droga que tem ação benéfica nas duas situações, ${ }^{18}$ podendo ser uma opção para outros serviços cujo os pacientes necessitem de equilíbrio entre imunossupressão na presença de uma agente infeccioso.

\section{ABSTRACT}

Polyomavirus nephropathy (BKV) occurs in 1.1\% to $9.3 \%$ of kidney transplant recipients, causing graft loss in more than $40 \%$ of cases. The primary infection occurs in the childhood, and the virus remains latent into the organism, becoming reactive under immunosuppressant conditions. We report a 45-year-old woman case recipient of a renal allograft three years ago, who was in chronic use of tacrolimus and mycophenolate mofetil, and presented progressive loss of renal function during a diarrheic episode despite the adequate treatment. Graft biopsy revealed the presence of cells with polyomavirus inclusions, being initiated sirolimus and human immunoglobulin. With the instituted therapeutic the renal function improved, and a new biopsy performed after hospital internment did not show histological alterations by polyomavirus.

Keywords: BK Virus; Kidney Transplantation; Immunosuppression 


\section{REFERÊNCIAS}

1. Prince O, Savic S, Dickenmann M, Steiger J, Bubendorf L, Mihatsch MJ. Risk factors for polyoma virus nephropathy. Nephrol Dial Transplant. 2009;24(3):1024-33.

2. Buehrig CK, Lager DJ, Stegall MD, Kreps MA, Kremers WK, Gloor JM, et al. Influence of surveillance renal allograft biopsy on diagnosis and prognosis of polyomavirus associated nephropathy. Kidney Int. 2003;64(2):665-73.

3. Fishman JA. Infection in solid-organ transplant recipients. N Engl J Med. 2007;357(25):2601-14.

4. Reploeg M, Storch G, Clifford D. BK virus: A clinical review. Clin Infect Dis. 2001;33:191-202.

5. Shah KV. Human polyomavirus BKV and renal disease. Nephrol Dial Transplant. 2000;15(6):754-5.

6. McNees AL, White ZS, Zanwar P, Vilchez RA, Butel JS. Specific and quantitative detection of human polyomaviruses BKV, JCV, and SV40 by real time PCR. J Clin Virol. 2005;34(1):52-62.

7. Nickeleit V, Singh HK, Mihatsch MJ. Polyomavirus nephropathy: morphology, pathophysiology, and clinical management. Curr Opin Nephrol Hypertens. 2003;12(6):599-605

8. Hirsch HH, Brennan DC, Drachenberg CB, Ginevri F, Gordon J, Limaye AP, et al. Polyomavirus-associated nephropathy in renal transplantation: interdisciplinary analyses and recommendations. Transplantation. 2005;79(10): 1277-86.

9. Bohl DL, Storch GA, Ryschkewitsch C, Gaudreault-Keener M, Schnitzler MA, Major EO, et al. Donor origin of BK virus in renal transplantation and role of HLA C7 in susceptibility to sustained BK viremia. Am J Transplant. 2005;5(9):2213-21.

10. Medeiros M, Alberú J, García GR, Fuentes Y, Velasquez L. Polyoma virus in transplant recipients. Nefrología. 2008;28(2)203-11.

11. Brennan DC, Agha I, Bohl DL, Schnitzler MA, Hardinger KL, Lockwood M, et al. Incidence of BK with tacrolimus versus cyclosporine and impact of preemptive immunosuppression reduction. Am J Transplant. 2005;5(3):582-94.

12. Mengel M, Marwedel M, Radermacher J, Eden G, Schwarz A, Haller H, et al. Incidence of polyomavirus-nephropathy in renal allografts: influence of modern immunosuppressive drugs. Nephrol Dial Transplant 2003; 18:1190-6.

13. Bohl DL, Koch MJ, Brennan DC. Viral Infections in Renal Transplantation: A Clue to Excessive Immunosuppression. J Bras Nefrol. 2007;29(3):185-90.

14. Brennan DC. Clinical manifestations and diagnosis of BK virus-induced (polyomavirus-induced) nephropathy in kidney transplantation. Disponível em: $<$ www.uptodate.com>. Acesso em 28 de fevereiro de 2010.

15. Hirsch HH: Polyomavirus BK nephropathy: A (re-)emerging complication in renal transplantation. Am J Transplant. 2002;2:25-30.

16. Hariharan S. BK virus nephritis after renal transplantation. Kidney Int. 2006;69(4):655-62.

17. Wali RK, Drachenberg C, Hirsch HH, et al. BK virus-associated nephropathy in renal allograft recipients: Rescue therapy by sirolimus based immunosuppression. Transplantation. 2004;78:1069-73.

18. Brennan DC. Management of BK virus-induced (polyomavirus-induced) nephropathy in kidney transplantation. Disponível em: <www.uptodate.com>. Acesso em 28 de fevereiro de 2010.

19. Farasati NA, Shapiro R, Vats A, Randhawa P. Effect of leflunomide and cidofovir on replication of BK virus in an in vitro culture system. Transplantation. 2005;79(1):116-8.

20. Josephson MA, Williams JW, Chandraker A, Randhawa PS. Polyomavirus- associated nephropathy: update on antiviral strategies. Transpl Infect Dis. 2006;8(2):95-101.

21. Hirsch HH, Ramos E. Retransplantation after polyomavirus-associated nephropathy: just do it? Am J Transplant. 2006;6(1):7-9. 